\title{
ON REFINED YOUNG INEQUALITIES AND REVERSE INEQUALITIES
}

\author{
SHIGERU FURUICHI
}

Abstract. In this paper, we show refined Young inequalities for two positive operators. Our results refine the ordering relations among the arithmetic mean, the geometric mean and the harmonic mean for two positive operators. In addition, we give two different reverse inequalities for the refined Young inequality for two positive operators.

Mathematics subject classification (2010): 15A45.

Keywords and phrases: Young inequality, reverse inequality, positive operator, operator mean, Specht's ratio and operator inequality.

\section{REFERENCES}

[1] F. Kittaneh And Y. ManasRah, Improved Young and Heinz inequalities for matrices, J. Math. Anal. Appl., 36 (2010), 262-269.

[2] M. TominaGa, Specht's ratio in the Young inequality, Sci. Math. Japon., 55 (2002), 583-588.

[3] W. SPecht, Zer Theorie der elementaren Mittel, Math. Z., 74 (1960), 91-98.

[4] J. I. FujII, S. IZUmino AND Y. SEo, Determinant for positive operators and Specht's theorem, Sci. Math. Japon., 1 (1998), 307-310.

[5] F. Kubo And T. Ando, Means of positive operators, Math. Ann., 264 (1980), 205-224.

[6] T. FURUTA AND M. YANAGIDA, Generalized means and convexity of inversion for positive operators, Amer. Math. Monthly, 105 (1998), 258-259.

[7] T. FuRUTA, Invitation to linear operators: From matrix to bounded linear operators on a Hilbert space, Taylor and Francis, 2002.

[8] T. FuRUTA, The Hölder-McCarthy and the Young inequalities are equivalent for Hilbert space operators, Amer. Math. Monthly, 108 (2001), 68-69.

[9] C. A. McCarthy, $C_{p}$, Israel J. Math., 5 (1967), 249-271.

[10] G. H. Hardy, J. E. Littlewood and G. Pólya, Inequalities, Cambridge University Press, 1952. 
[11] P. S. Bullen, Handbook of Means and Their Inequalities, Kluwer Acad. Publ., Dordrecht, 2003.

[12] S. S. DRAGOMir, Bounds for the normalised Jensen functional, Bull. Australian Math. Soc., 74 (2006), 471-478. 